LA-UR-

$96-24 \underset{\text { Tite: }}{\mathbf{5}}$

THE DESIGN AND PERFORMANCE OF THE RESEARCH REACTOR FUEL COUNTER

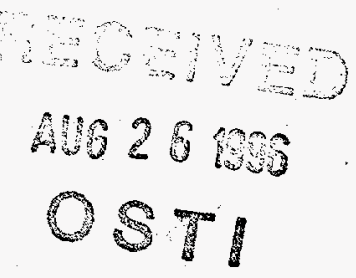

Author(s): M. E. Abhold, S. T. Hsue, H. O. Menlove, G. Walton, and S. Holt

Submitted to:

37th Institute of Nuclear Materials Management Meeting Naples, FL USA

July 28-31, 1996

(FULL PAPER)

BYSTPIBITON OF THIS DOCUMENT IS UNLIMTED
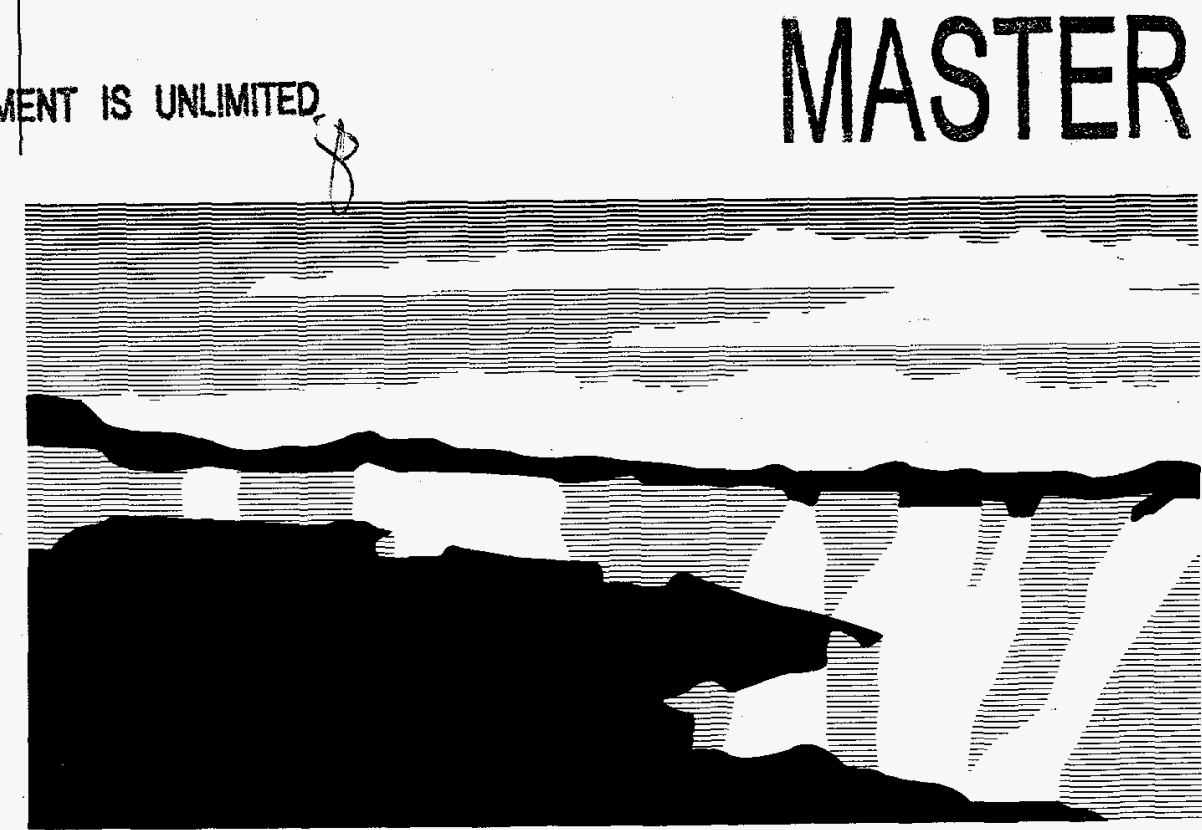

Los Alamos National Laboratory, an affirmative action/equal opportunity employer, is operated by the University of California for the U.S. Department of Energy under contract W-7405-ENG-36. By acceptance of this article, the publisher recognizes that the U.S. Government retains a nonexclusive, royalty-free license to publish or reproduce the published form of this contribution, or to allow others to do so, for U.S. Government purposes. The Los Alamos National Laboratory requests that the publisher identify this article as work performed under the auspices of the U.S. Department of Energy. 


\section{DISCLAIMER}

Portions of this document may be illegible in electronic image products. Images are produced from the best available original document. 


\title{
THE DESIGN AND PERFORMANCE OF THE RESEARCH REACTOR FUEL COUNTER*
}

\author{
M. E. Abhold, S.-T. Hsue, H. O. Menlove, G. Walton, and S. Holt \\ Los Alamos National Laboratory \\ Los Alamos, NM 87545 USA
}

\begin{abstract}
This paper describes the design features, hardware specifications, and performance characteristics of the Research Reactor Fuel Counter (RRFC) System. The system is an active mode neutron coincidence counter intended to assay material test reactor fuel assemblies under water. The RRFC contains $12{ }^{3} \mathrm{He}$ tubes, each with its own preamplifier, and a single ion chamber. The neutron counting electronics are based on the Los Alamos Portable Shift Register (PSR) and the gamma readout is a manual-range pico-ammeter of Los Alamos design. The RRFC is connected to the surface by a 20 -m-long cable bundle. The PSR is controlled by a portable IBM computer running a modified version of the Los Alamos neutron coincidence counting code also called RRFC. There is a manual that describes the RRFC software.
\end{abstract}

\section{INTRODUCTION}

The measurement of the fissile content of spent fuel assemblies has been one of the more difficult nondestructive assay problems. The assay is difficult for several reasons:

- spent fuels have relatively high radiation fields $\left(10^{4} \sim 10^{6} \mathrm{R} / \mathrm{hr}\right)$ owing to fission products,

- the fissile content is usually a small portion of the heavy metal,

- the distribution of the heavy metal is quite heterogeneous,

- the fissile content is not uniformly distributed along the assembly, and

- the calibration of the assay instrument is hard because of difficulty in characterizing spentfuel assemblies without destroying the standard. Because of these difficulties, most spentfuel assays only measure fission products or the Curium content and are in general only used as consistency measurements.

Of the many types of spent fuels, material test reactor (MTR) spent fuel is unique. These are the fuel assemblies used to power the MTR reactors that are widely used around the world as research, development, and educational tools for nuclear scientists. MTR reactors also provide intense neutron beams which can be used for development in many areas of science such as nuclear and solid state physics, material science, and biology.

MTR fuel is nominally made from $93 \%$ enriched uranium and aluminum alloy. The alloy metals are rolled into thin layers and then covered with aluminum cladding. The plates are welded into assemblies such as "Venetian blinds" or concentric tubes. The original fissile content ranges from $\sim 220$ to $250 \mathrm{~g}$ of ${ }^{235} \mathrm{U}$ and burnup ranges from $20 \%$ to $60 \%$; the spent fuel contains 80 to $180 \mathrm{~g}$ of ${ }^{235} \mathrm{U}$. The burnup is usually a cosine shape along the length of the assembly because MTR reactors are fairly leaky from a neutronic standpoint; consequently, the fissile content is lower at the middle of the assembly as compared to the ends.

To verify the fissile content of spent MTR assemblies, we have designed and fabricated a Research Reactor Fuel Counter (RRFC) that was developed to assay MTR spent fuel under water in a spent fuel pool. The device assays the ${ }^{235} \mathrm{U}$ content by active neutron interrogation using AmLi sources. Coincidence counting of the induced fission neutrons is performed by shift register electronics. An ion chamber is also incorporated for gross gamma-ray measurements. One of the most interesting aspects of the RRFC is that the instrument can be calibrated with a fresh MTR fuel assembly, making the assay a direct measurement of the fissile content. This paper will describe the features of the counter and its performance in our test laboratory. We will also discuss the calibration procedure for the device. Further details are contained in the RRFC hardware manual. ${ }^{1}$

\section{SYSTEM COMPONENTS}

\section{A. General}

The RRFC contains $12{ }^{3} \mathrm{He}$ tubes, each with its own separate preamplifier, polyethylene neutron moderator, and lead gamma shielding; $2 \mathrm{AmLi}$ interrogation sources;

\footnotetext{
* This work is supported by the US Department of Energy, Savannah River Site, Operations Office.
} 

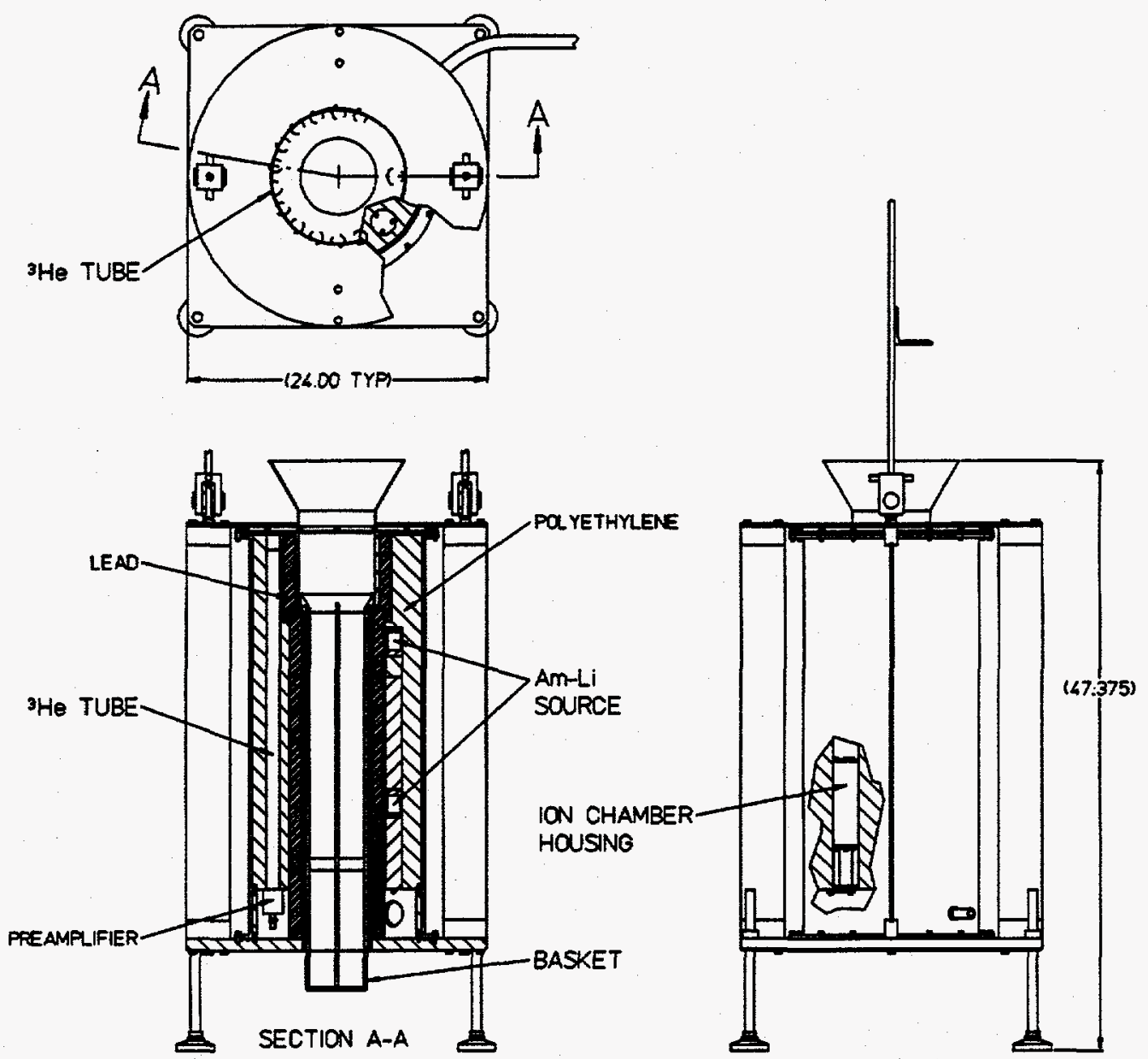

Fig. 1. Schematic diagram of the RRFC detector, showing the location of the ${ }^{3} H e$ tubes, the AmLi neutron sources, the ion chamber, and the preamplifiers.

and an ion chamber in a sealed stainless-steel housing. A schematic diagram of the RRFC is shown in Fig. 1. MTR assemblies are loaded from the top; a funnel aids in the loading process. A grappling tool can be inserted into the topmost section of the central cavity of the counter, which has been enlarged to allow easy access for insertion and withdrawal. The fuel assembly to be measured is centered within the central cavity of the detector by baskets that are designed to fit each specific type of MTR assembly.

Fig. 2 is a photograph of the body of the detector; Fig. 3 is a photograph of the polyethylene. insert with the preamplifiers installed.

\section{B. ${ }^{3} \mathrm{He}$ Tubes}

The RRFC contains $12{ }^{3} \mathrm{He}$ tubes that efficiently count neutrons emitted from the fuel assembly. Each tube has a 2.5-cm diameter and $61-\mathrm{cm}$ active length. The fill-pressure is four atmospheres of ${ }^{3} \mathrm{He}$ with a nitrogen quenchgas additive. The tubes are made of aluminum and have an internal carbon coating for gamma resistance. These tubes are specially constructed to minimize gamma sensitivity. ${ }^{2}$

The ${ }^{3} \mathrm{He}$ tubes are arranged in a semicircle around the central cavity. This arrangement was selected to limit the total neutron count rate coming from the AmLi interrogation sources while still maintaining acceptable counting efficiency for neutrons coming from the fuel. Each ${ }^{3} \mathrm{He}$ tube has its own preamplifier to maximize gamma rejection. The signals from six preamplifiers are "daisy chained" to form two symmetric banks of six tubes each, with a separate signal cable going to the surface from each bank. The signals from the two banks are combined in an adder circuit for normal operation, or each bank can be counted independently for diagnostic purposes. 


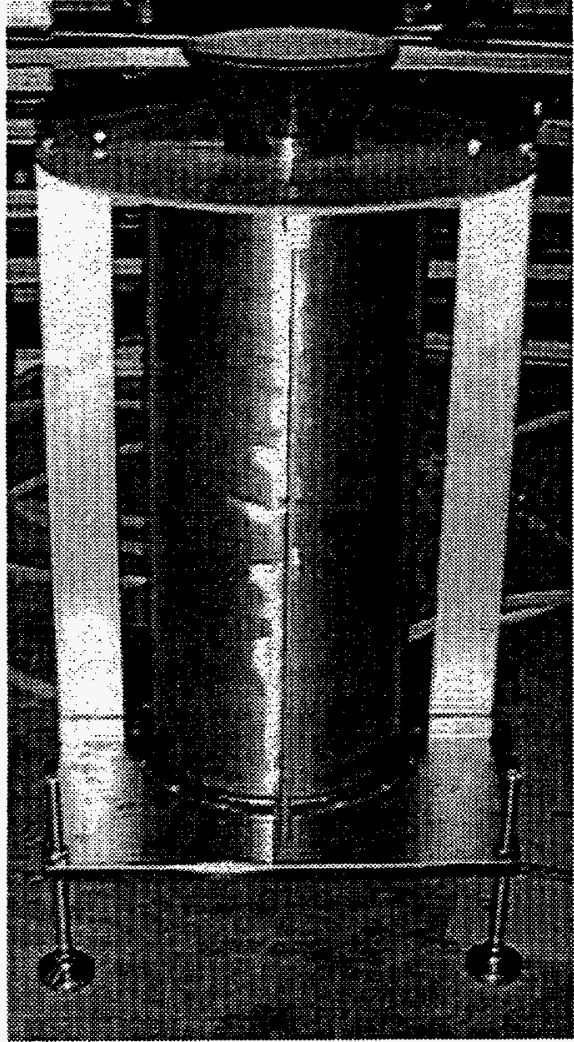

Fig. 2. Photograph of the RRFC detector body.

The preamplifiers are powered by a $5-\mathrm{V}$ cable from the portable shift register (PSR) at the surface. The $5-\mathrm{V}$ supply is "daisy chained" to all 12 preamplifiers.

\section{C. ${ }^{3}$ He Tube Tests}

The counting efficiency for each tube/preamplifier was measured in a fixed geometry with a ${ }^{252} \mathrm{Cf}$ source. The preamplifier gain was then adjusted to match the count rate across all the tubes. One tube was then taken into the hot cell for gamma-pileup testing with an AmLi neutron source and ${ }^{226} \mathrm{Ra}$ gamma source. The measured detector-bias plateau and gamma pileup behavior for the one bare tube are shown in Fig. 4.

Some gamma pileup was observed at $50 \mathrm{rad} / \mathrm{hr}$ at $1700 \mathrm{~V}$. Therefore, in order to reduce the sensitivity to the gamma flux, the operating voltage was set at $1680 \mathrm{~V}$. At 1680 $\mathrm{V}$, gamma pileup is not observed at $50 \mathrm{rad} / \mathrm{hr}$ and only minimal pileup is observed at $100 \mathrm{rad} / \mathrm{hr}$. The $100 \mathrm{rad} / \mathrm{hr}$ at the tube is equivalent to a dose rate of over 10,000 $\mathrm{rad} / \mathrm{hr}$ at the MTR assembly surface. In addition, as the active assay results are based on neutron coincidence counting, the coincidence counting provides additional gamma-ray rejection.

\section{Neutron Interrogation Sources}

The RRFC contains two 1.2-Ci AmLi neutron sources. Each source supplies approximately $5.5 \times 10^{4}$ uncorrelated neutrons per second which induce fissions in the fuel assembly. The sources each interrogate roughly $16 \mathrm{~cm}$ along the length of the fuel assembly. The two sources are separated axially along the fuel to minimize RRFC sensitivity to the fuel burnup profile. MTR fuel has a strong burnup profile, with the center of the fuel assembly having the highest burnup and the ends being low in comparison. With the assembly correctly placed into the counter, each of the two neutron sources cause nearly the same number of fissions and create the same number of coincidence counts. If the assembly is placed into an offcenter position in the counter, either high or low, one source will interrogate a portion of the assembly with higher-than-average burnup while the other will see lower-than-average burnup, effectively compensating for each other.

\section{E. RRFC Calibration Procedure}

Calibration parameters for the RRFC are derived by calculation for each separate type of spent fuel assembly. Calibration by calculation, rather than by measurement, is necessary because of the lack of suitably characterized MTR-type spent fuel assembly standards. However, calibration of the RRFC for fresh fuel is possible by measuring adequately characterized fresh fuel assemblies, thereby providing a benchmark for the spent fuel calculations.

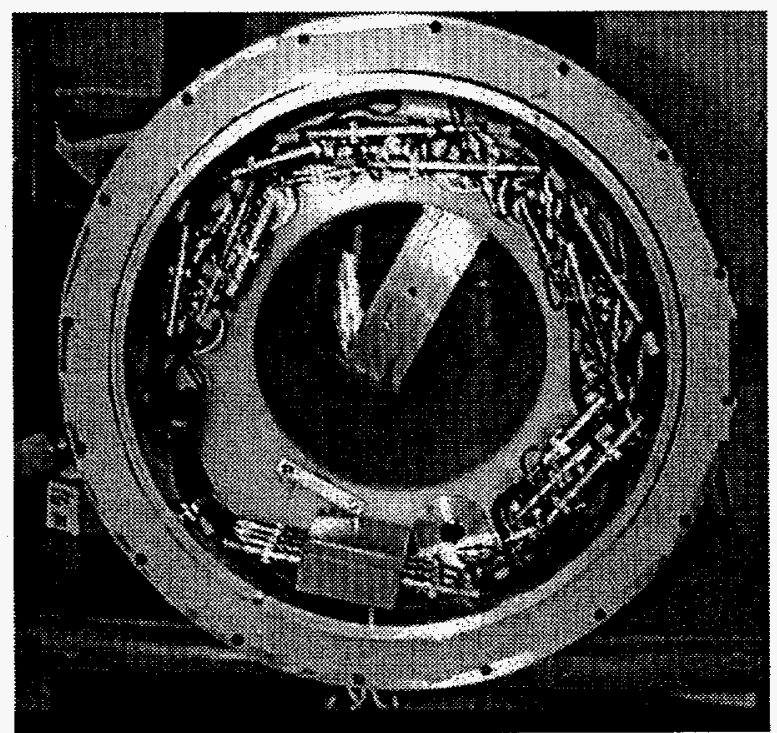

Fig. 3. Photograph of the polyethylene moderator and preamplifiers. 


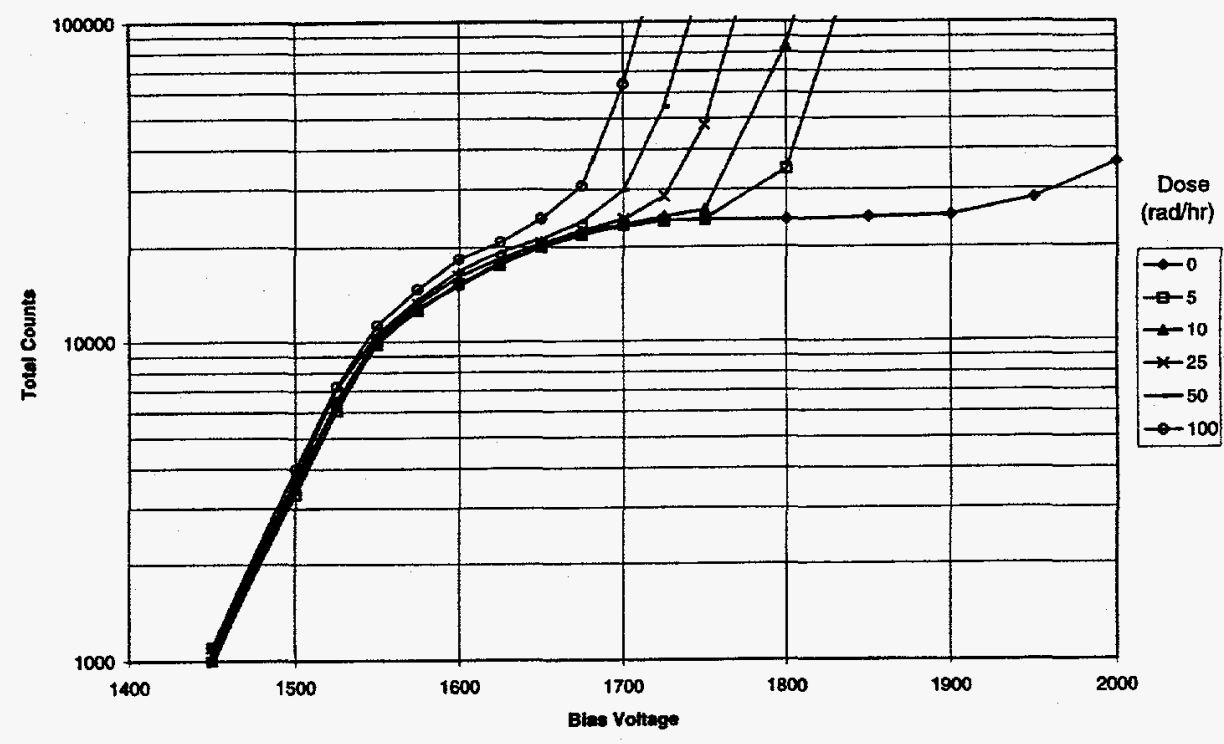

Fig. 4. Detector bias plateau and gamma pileup behavior for the ${ }^{3} \mathrm{He}$ tube and Precision Data Technology Preamplifier.

Calibration calculations were performed using the threedimensional Monte Carlo neutron-transport code MCNP. ${ }^{1}$ An MCNP model was constructed that contains the dimensions, compositions, and densities of all materials used in the RRFC. The model allows the code to predict the reaction rates in the ${ }^{3} \mathrm{He}$ tubes per source AmLi neutron, the fission and radiative capture rates in the assembly, and other necessary parameters. Output of the MCNP code, along with information from the measured ${ }^{3} \mathrm{He}$ tube voltage response curve, was used to calculate the doubles rate and other parameters. This process was repeated for several ${ }^{235} \mathrm{U}$ masses, with the curve through the mass vs doubles rate forming the calculated calibration for the MTR assembly. It is important that the MTR fuel assembly model be accurate, as the neutron multiplication and hence the doubles rate is very sensitive to the geometry of the assembly.

\section{F. Validation of the Calculational Model for Fresh Fuel}

The calculational model was validated by comparison to measurements made on a fresh MTR test assembly that can be disassembled and configured with varying numbers of plates in various geometries. Measurements were made to cover the range from $85 \mathrm{~g}$ to $184 \mathrm{~g}$ of ${ }^{235} \mathrm{U}$, and a fit was performed on the measured data points using a function of the form

$$
R=\frac{a m}{1+b m}
$$

where $R$ is the doubles rate, $m$ is the ${ }^{235} \mathrm{U}$ mass, and $a$ and $b$ are fit constants.

Fig. 5 shows the result of the comparison between calculated and measured calibration curves.

Another set of measurements was taken to determine the die-away time of the counter. The measured value was then compared with the calculated die-away time of the counter, providing another means to validate the calculational model. The measured value was $111 \mu \mathrm{s}$, the calculated value was $112 \mu \mathrm{s}$.

\section{G. RRFC Calibration for Spent Fuel}

Fission products build up in the MTR fuel assembly as it is irradiated in a reactor. Some of these fission products are effective neutron absorbers. Transuranic elements also build up (principally ${ }^{238} \mathrm{Pu}$ ) and cause alpha-n reactions in the aluminum; these reactions provide an additional source of neutrons. These two effects are partially compensating - the neutron absorbers reduce the number of neutrons that are counted per gram of fissile material and the alpha-n reactions increase the number counted. However, as burnup increases beyond about $50 \%$, the alpha-n production starts to overcome the fission product neutron absorption and a greater number of neutrons are emitted from the fuel per gram than for fresh fuel. Lowburnup fuel can be adequately assayed using the fresh fuel calibration; however, very high burnup spent fuel requires a separate calibration curve from that for fresh fuel. 


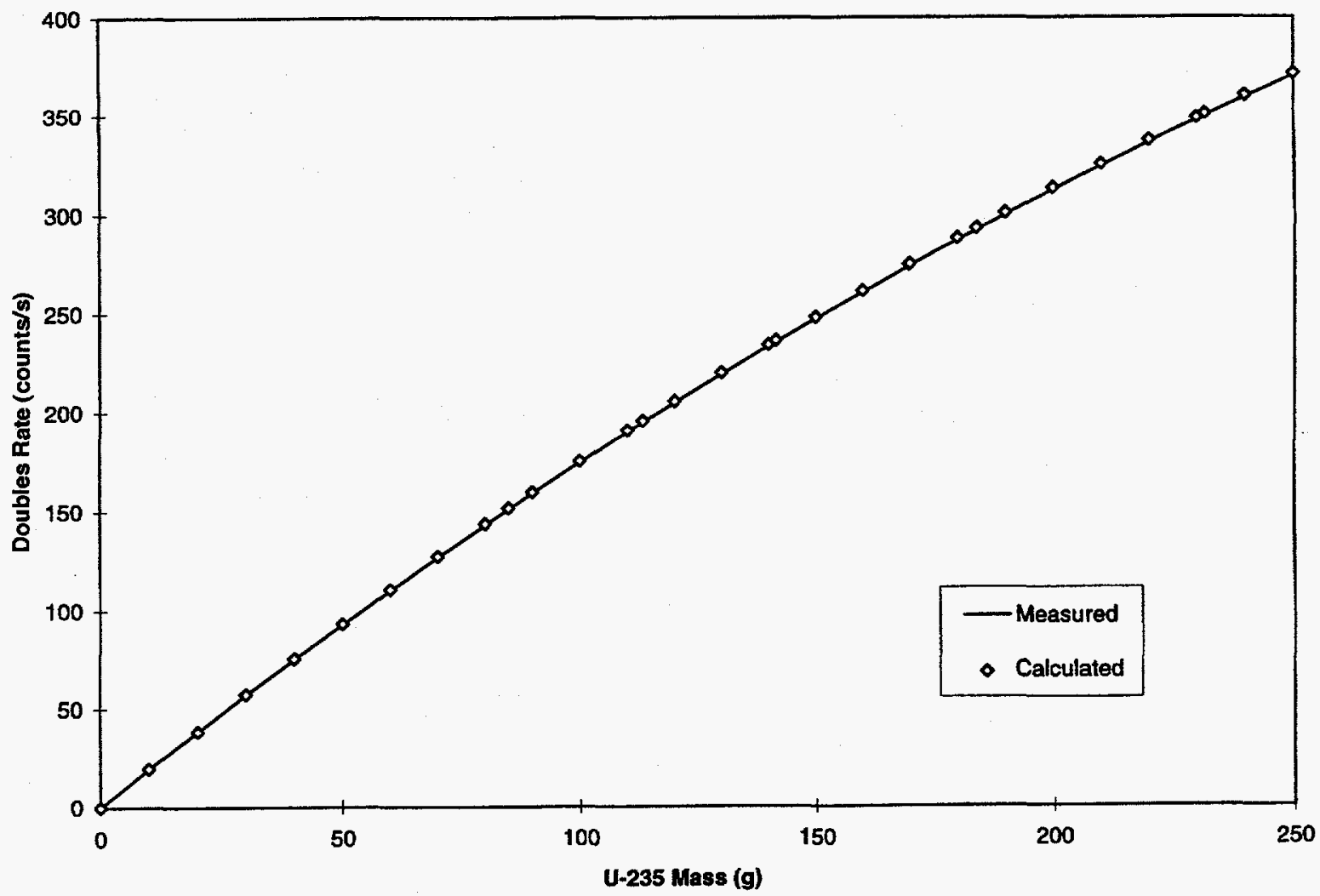

Fig. 5. Measured vs calculated RRFC calibration curve.

Currently, adequately characterized calibration standards for spent MTR fuel are not available. Therefore, the same basic calculational method described above for fresh fuel is used to obtain the calibration for spent fuel. In addition to the basic calculation, additional calculations must be performed to predict the amount and isotopic composition of the fission products as well as the alpha-n neutron production rate.

\section{H. RRFC System Performance Summary}

Measurements were made on fresh MTR fuel to determine the precision, bias, and sensitivity to the loaded position of the fuel. The performance and important parameters of the RRFC are summarized in Table $I$.

\begin{tabular}{|c|c|}
\hline Parameter Description & Value \\
\hline Efficiency & $13 \%$ \\
\hline Die-Away Time & $111 \mu \mathrm{s}$ \\
\hline Doubles Gate Length & $128 \mu \mathrm{s}$ \\
\hline Accuracy $(5 \mathrm{~min}$ count, $>80 \mathrm{gm}$ 235 $\mathrm{U})$ & Better than $4 \%$ \\
\hline Precision (5 min count, $\left.>80 \mathrm{gm}^{235} \mathrm{U}\right)$ & Better than 3\% \\
\hline AmLi Source Strength & $1.1 \times 10^{5}$ neutrons $/ \mathrm{s}$ (total) \\
\hline Gamma Rejection Capability & $12,000 \mathrm{rad} / \mathrm{hr}$ (assembly surface) \\
\hline Sensitivity to Angular Displacements $<45^{\circ}$ & $<0.2 \%$ \\
\hline Sensitivity to Axial Displacements & $<0.5 \%$ \\
\hline Unit Weight & $750 \mathrm{lb}$ \\
\hline
\end{tabular}




\section{REFERENCES}

1. M. E. Abhold, S. T. Hsue, H. O. Menlove, and G. Walton, "Research Reactor Fuel Counter Operation Manual," Los Alamos National Laboratory report LA-13152-M, (May 1996).

2. H. O. Menlove and D. H. Beddingfield, "The Development of ${ }^{3} \mathrm{He}$ Neutron Detectors for Applications in
High Level Gamma-Ray Backgrounds," Proceedings of the 4th Nondestructive Assay and Nondestructive Examination Waste Characterization Conference, Salt Lake City, Utah (October 1995).

3. J. F. Briesmeister (ed.), "MCNP-A General Monte Carlo N-Particle Transport Code," Los Alamos National Laboratory report LA-12625-M, Ver. 4A (Nov. 1993).

\section{DISCLAIMER}

This report was prepared as an account of work sponsored by an agency of the United States Government. Neither the United States Government nor any agency thereof, nor any of their employees, makes any warranty, express or implied, or assumes any legal liability or responsibility for the accuracy, completeness, or usefulness of any information, apparatus, product, or process disclosed, or represents that its use would not infringe privately owned rights. Reference herein to any specific commercial product, process, or service by trade name, trademark, manufacturer, or otherwise does not necessarily constitute or imply its endorsement, recommendation, or favoring by the United States Government or any agency thereof. The views and opinions of authors expressed herein do not necessarily state or reflect those of the United States Government or any agency thereof. 